\title{
MAL-ESTAR NA EDUCAÇÃO: O TRIUNFO DO DISCURSO DO MESTRE SEGUNDO LACAN
}

\author{
Hildemar Luiz Rech ${ }^{1}$ \\ Hipácia Rocha Lima
}

\begin{abstract}
Resumo
Esse artigo busca investigar a relação do discurso capitalista com o modelo de educação contemporânea através da psicanálise lacaniana. Para tanto, o estudo parte da teoria dos discursos, a fim de interrogar determinados aspectos das políticas educacionais que implicam na práxis pedagógica. Conforme o entendimento de Jacques Lacan, os discursos estabelecem laços sociais que são verdadeiros elos de coletividade, uma vez que as estruturas da linguagem exercem domínio sobre as práticas do sujeito, fazendo reverberar na política, na cultura, no conhecimento e nas ideologias em geral. Desse modo, o ponto de elaboração da problemática encontra-se em pensar a educação contemporânea a partir dessa interface do discurso capitalista, que, muitas vezes, intervém no ato educativo, por meio da pressão pelo sucesso escolar, ocasionando o adoecimento precoce dos jovens, rotulando o sujeito em resultados normativos e até mesmo na produção em massa de capital humano, e assim gerando um Mal-estar na educação. Tal perspectiva será trabalhada por meio da leitura da obra de Lacan O avesso da psicanálise (1969-1970), de maneira a destacar o discurso capitalista na mediação social da linguagem via agendamentos do sujeito e na incorporação das relações institucionais de ensino atual.
\end{abstract}

Palavras-chave: Educação. Discurso. Capitalismo. Psicanálise.

\section{DISCONTENTS IN EDUCATION: THE TRIUMPH OF THE MASTER'S SPEECH ACCORDING TO LACAN}

\begin{abstract}
This article seeks to investigate the relationship of capitalist discourse with the model of contemporary education through Lacanian psychoanalysis. Therefore, the study starts from the theory of discourses, in order to interrogate certain aspects of educational policies that imply pedagogical praxis. According to Jacques Lacan's understanding, the discourses establish social ties that are true links of the collectivity, since the language structures exert control over the subject's practices, reverberating in politics, culture, knowledge and ideologies in general. Thus, the point of elaboration of the problem lies in thinking about contemporary education from this interface of the capitalist discourse, which often intervenes in the educational act, through pressure for school success, causing young people to fall ill early, labeling the subject in normative results and even in the mass production of human capital, and thus generating a malaise in education. This perspective will be developed through the reading of Lacan's work The opposite of psychoanalysis (1969-1970), in order to highlight the capitalist discourse in the social mediation of language via the subject's agendas and in the incorporation of institutional relations in current education.
\end{abstract}

Keywords: Education. Speech. Capitalism. Psychoanalysis.

1 Doutor em Ciências Sociais pelo IFCH da UNICAMP, SP, com estágio doutoral (como Visiting Researcher) na Universidade de Manchester, Inglaterra; Pesquisador e Professor Associado IV no Departamento de Fundamentos da Educação e na Linha de Pesquisa de Filosofia e Sociologia da Educação no Programa de Pós-Graduação em Educação, FACED-UFC. Orcid: http://orcid.org/00000002-5825-1887. E-mail: hluizrech@gmail.com.

2 Mestranda em Educação Brasileira pela Universidade Federal do Ceará (UFC). Graduada em Filosofia pela Universidade Estadual do Ceará - UECE. Orcid: http://orcid.org/000-0002-1505-9975. E-mail: hipacialiam@gmail.com. 


\section{INTRODUÇÃO}

À primeira vista, discorrer a respeito de um triunfo na educação soa no mínimo como uma controvérsia, principalmente quando se refere ao quadro atual do ensino público, que vem agonizando com uma precarização generalizada. É exatamente sobre esses desafios da educação pública que se revela a verdadeira face do triunfo: a inclinação neoliberal das escolas. As dificuldades não se limitam à aplicação da lei ou das reformas, mas também se encontram em torno de uma ordem global e estrutural dos discursos políticos e econômicos, a qual sustenta e sujeita a educação ao grande mestre moderno, o capitalismo, já que em tempos de poder capital, o conhecimento tornou-se aquilo que compramos e vendemos com ele, um bem material para investimento. Dentro desse aspecto, consideramos que os interesses neoliberais se sobrepõem no ambiente educacional, contribuindo significativamente para a segregação e para os impasses sobre o currículo escolar, de tal forma que ainda hoje ecoa a pergunta piagetiana: "Para onde vai a educação?". Nesse sentido, procuramos apresentar neste artigo como a Teoria dos Discursos, formulada pelo psicanalista Jacques Lacan (1901-1981), explicaria e complementaria a hipótese da inserção da lógica capitalista no campo educacional, bem como, de que maneira a ordem do discurso econômico passou a orientar também o papel da escola, principalmente em países periféricos, nas últimas décadas, ou seja, objetiva-se compreender, à luz da ferramenta psicanalítica, como o discurso capitalista engendrou laços sociais na educação atual. Esse é um cenário de conflitos em que a psicanálise tem buscado nomear seus reflexos, notadamente conhecida na tradição como Mal-estar.

Estudar a escola sobre tal perspectiva impõe compreendê-la dentro de um conjunto integrado de estruturas materiais e simbólicas que produzem e reconstroem práticas que, segundo Moscovici (1978), implicam em uma relação de representação social entre o sujeito (professor) e o objeto (escola). Talvez por isso a escola se torna um espaço que propicia agrupar processos de várias ordens, de conflitos, de experiências e de mudanças, uma vez que perpassam nesse lugar o costume, o conhecimento, os sentimentos, as ideologias, as rupturas, de segregação de classes, sendo um macro e um microcosmo. Além disso, é um ambiente de encontros subjetivos e intersubjetivos que possibilitam circular histórias. Assim, nesse espaço institucional - a escola - coabita também o lugar real das tensões entre a reprodução do status quo e a oportunidade de emancipação, arena onde os indivíduos se institucionalizam com os conhecimentos 
legítimos, mas, por outro lado, buscam resistir na prática reflexiva do ato de educar. De forma geral, a cultura escolar parece mais submetida às mudanças criadas pelo discurso dominante, elegendo a tecnologia como solucionadora dos problemas da educação (VOLTOLINI, 2011).

Ao nos debruçarmos sobre a dimensão psicossocial presente no âmbito escolar, isto é, considerando que sujeito ${ }^{3}$ e sociedade se realizam de forma conjunta e dinâmica (MÉSZÁROS, 1981) através das esferas cognitiva, histórica, afetiva, biológica, objetiva e social, tomamos essa também como base para pensar as vulnerabilidades de crianças e adolescentes pela repercussão na aprendizagem e pelos impactos ao longo da vida. Assim, recorremos à base psicanalítica de Jacques Lacan como pontapé inicial para refletir acerca dos desafios sobre a educação atual, no que tange à ordem econômica como instância fundante dessa emblemática situação.

A função da psicanálise não se reduz ao campo individual ou psíquico somente, nem é apenas uma ciência com o fim de manejar dores psicológicas deslocadas da psiquiatria, como costumam enquadrar as críticas, mas vai além, pois por sua especificidade, crítica e método analítico, ela abre e possibilita dar voz e escuta a um sujeito à deriva, destacando a emergência da saúde mental e da vulnerabilidade humana na era contemporânea, e assim contribuindo para a discussão em meio aos estudos sobre a sociedade.

Freud não se eximiu do debate a respeito do fenômeno social quando tratou na obra Mal-estar na civilização (1930-36) sobre o antagonismo presente entre o rompante dos desejos e a ordem da cultura e dos bons costumes, fato que delata aquilo que as nossas pulsões insistem em desmentir. Na mesma linha, Lacan fala sobre a marca da nossa singularidade, indo da metáfora à letra no inconsciente, posto que, diante do implacável, do impossível de suportar, o sujeito faz um sintoma. Somos sensíveis às consequências que produzimos, elas retroagem de alguma forma, tornando-se determinantes sócio-históricos que influenciam o pensamento e o comportamento. Dessa maneira, percebemos nos primeiros seminários de Lacan que a construção da realidade

3 Devemos citar que o sujeito que consideramos no estudo é o sujeito do inconsciente, o sujeito do desejo, das pulsões, do mais-gozar, representado aqui por aquilo que o discurso capitalista procura usurpar, dele nutri sua mola propulsora. Para Lacan, o sujeito é um lugar a priori vazio, sem atributos definidos, dependendo da predição de significantes, ficando assinalado pela constante possibilidade de vir-a-ser, chamado pelo autor de sujeito clivado. Assim, a pesquisa inclina-se para o sujeito do inconsciente, mas também, assinala para aquele vem a ser atravessado pela luz da linguagem, haja vista, que Lacan afirmava o sujeito do inconsciente ser estruturado pela linguagem (LACAN, 1966, pág 125). 
fica quase indissociável do registro do real, esse real que desequilibra e traumatiza, parecendo fora de sentido, mas por onde o tecido social anuncia seus tipos de adoecimento. Tal acepção sinaliza como Lacan identificava no filósofo Karl Marx (18181883) um pensador que na sua inquietação alcançou uma compreensão psicossocial, quando, a partir da questão da exploração do trabalho, do tempo socialmente necessário à produção da mercadoria, eclodiu o adoecimento do sujeito, ou melhor, descobriu-se um sintoma social na expressão da labuta, na luta de classe, no sistema de produção que gerou o acúmulo de riqueza da burguesia, dada a angústia do trabalhador, a melancolia vivida, o sofrimento e a fragilidade dos corpos, muitas vezes inertes e alienados da realidade. Nessas condições, para Lacan, de certa forma, Marx identificou um problema concreto no domínio dos fenômenos psicológicos, fez um retrato sintomático do proletariado na era industrial, via exploração do trabalho. No Seminário 22, Lacan afirma: "A noção de sintoma foi introduzida bem antes de Freud por Marx como signo do que não anda bem no real" (LACAN, 1974/75, sessão de 10).

No que se refere à incidência do discurso capitalista sobre as práticas pedagógicas contemporâneas, podemos afirmar inicialmente que existe um discurso dominante no campo educacional, cuja marca se inscreve na perda de autonomia da escola (RAHME, 2012). De fato, isso assinala uma preocupação para muito teóricos, pois a legislação garante essa liberdade para descentralizar as decisões e responsabilidades, mas as escolas continuam sofrendo controle em excesso de instâncias superiores. Posto isso, identificamos a nova forma de organização da educação, que se inspira no gerenciamento econômico de negócio, conservando, ainda, os moldes tradicionais de autocracia e hierarquia (PASSONE, 2012). Assim, esse modelo de gestão de ensino segue na direção para reforçar a aprendizagem por meio de desempenho e rendimento, na busca pelo desenvolvimento de habilidades e competências convenientes para o mercado, na ênfase da transmissão do conteúdo, na técnica e no comportamento, dentre outros aspectos que levam a crer, engenhosamente, na produção em massa de capital humano. Dessa forma, o valor da autonomia escolar fica diluído em projetos pedagógicos ou na função de 'representar' os interesses da sociedade capitalista, ao invés de defender as necessidades da população que é acolhida. Nesse contexto, a democratização do ensino como parte inerente da autonomia da escola fica barrada por normas e orientações delineadas e cobradas por instâncias externas às instituições de ensino. Essa conjuntura, oportunamente, desenvolve formas de discursos que se valem para tecer condutas e 
ideologias sociais, principalmente nas ações insidiosas e silenciosas da típica presença do capitalismo globalizado na educação (RAHME, 2012).

Sinteticamente, indo em direção a uma noção ampliada da proposta aqui tratada, compreende-se que a globalização contemporânea (SAFATLE, 2021) também pode abranger, dentre outros aspectos, aquela finalidade poderosa do capitalismo em dispor uma nova lógica civilizacional para o resto do mundo, um tipo de ocidentalização dos modos de existência. Nesse sentido, ela traz consigo a tendência falaciosa de única opção ou estratégia bem sucedida de modelo adotado, pelo estilo de vida e comportamento social intrínseco. É como parte integrante desse processo que muitos países subdesenvolvidos buscam um "voucher" no âmbito dos valores democráticos, através da adoção dos direitos humanos e de padrões ecológicos, na tentativa de entrar na elite geopolítica e de obter fundos de investimentos para indicadores e interesses privados (PASSONE, 2013). Mas, na prática, tal barganha pouco se relaciona com o desenvolvimento social e com o valor da educação, ou com uma política assentada na democracia, pois a aplicabilidade das decisões e a fiscalização do Estado apresentam-se difusas e restritivas quanto ao poder econômico assumido pelo capitalismo global. Na verdade, o jogo de forças assegura essa dimensão econômica e uma organização política assumida pela globalização capitalista que seja, simultaneamente, reforço das funções socioeconômicas, políticas e culturais (SAFATLE, 2021). Nessa medida, ao pensar nas perspectivas de futuro no contexto da escola atual, cabe lembrar também dos interesses que circulam no quadro de sucateamento do ensino público e da ênfase no ensino profissional, pois o acesso à educação não significa sincronicamente democratização de oportunidades e igualdade. Conforme Laval,

Em todas as instituições internacionais nas quais as sociedades ocidentais poderosas estão envolvidas é consensual a ideia de que países que buscam filiarse a instituições internacionais, receber ajuda da 'comunidade internacional' ou associar-se aos Estados Unidos, à OTAN, à OCDE etc. precisam passar no 'teste da democracia', de modo a assegurar direitos humanos e padrões ecológicos mínimos. A transparência democrática e o respeito aos direitos humanos são entendidos como ingredientes irrenunciáveis de 'boa governança' (LAVAL, 2004 p. 93).

Diante da aparente ausência dos preceitos democráticos, que balizam o papel da educação mediante a função social da escola, a pergunta sobre "para onde vai a educação?" lança luz sobre os objetivos fundamentais do ensino e da formação do cidadão, aqueles pelos quais atualmente muitas instituições parecem passar ao largo, relegando a segundo plano a Lei de Diretrizes e Bases da Educação Nacional - 9.394/96

\begin{tabular}{|c|c|c|c|c|}
\hline Qevista Dialectus & Ano 10 & n. 24 & Setembro - Dezembro 2021 & p. 177 - 196 \\
\hline
\end{tabular}


- quanto à importância dos valores humanos, da aquisição de cultura e dos conhecimentos socialmente construídos, ganhando outra significação, que seja da educação se reduzir a um serviço prestado ao mundo econômico, ou seja, uma educação que mantém um caráter de reprodução social içada pela falácia do progresso econômico, atuando, na realidade, na inversão dos princípios democráticos no próprio interior da escola (CÁSSIO\&HADDAD, 2019). Esse novo modelo escolar sujeito à razão econômica converte os sujeitos à mera coisa, regidos pelo mais-gozar, fragilizados pelas incertezas, endividados, movido por um individualismo ambicioso propenso à perda do valor à vida, em que, talvez, a psicanálise possa oferecer seu contributo.

Entretanto, quando a Psicanálise entra na polis e faz algumas interpretações dos fenômenos políticos, ela traz outro ponto de reflexão, pois aqueles grilhões que impõem suas amarras morais e de identificação para o sujeito não possuem ramificações apenas em uma elite geoeconômica ou imperialista, mas também nos liames sociais que regulam, vigiam e sustentam uma cadeia de discursos dominantes e alienantes (NAZIO, 1995). Desse "lugar" da psicanálise na política, da leitura do indivíduo quase indissociável do coletivo, do global e do público, surge um novo sentido de experiência científica para compreensão das transformações mundiais da sociedade e de suas instituições. Do reconhecimento de tal realidade, uma ampla classe intelectual francesa do século XX, dentre eles Pierre Bourdieu, Michel Foucault, Louis Althusser, Jacques Lacan, dentre outros, contribuíram significativamente para explicar a perda progressiva das condições de vida e de trabalho, e, principalmente, das instituições educativas, universitárias e científicas.

De fato, é importante sair um pouco daquela visão utópica sobre a educação, de saber quais as perspectivas reais de transcender determinada alienação ${ }^{4}$ que vem à tona também nos sistemas de ensino. Na verdade, qualquer que seja o modelo adotado sobre as práticas educacionais e pedagógicas, ele dependerá dos seus objetivos e fins específicos, da forma de aplicabilidade, da contribuição para a manutenção no intercâmbio social e nas condições sócio-históricas (MÉSZÁROS, 1981, pág. 260). Assim, o que está em jogo não é apenas a modificação política das instituições de educação formal, mas os discursos das políticas educacionais e o discurso no campo

4 Segundo István Mészáros: “a busca por uma significação contemporânea da teoria da alienação, é quase uma tarefa impossível, pelas várias interpretações sistemáticas que a teoria pode ganhar, quando Marx investiga os aspectos históricos e sistemáticos-estruturais da alienação em relação a vida real e seus reflexos" (1981, pág. 92).

\begin{tabular}{|l|l|l|l|l|}
\hline Revista Dialectus & Ano 10 & n. 24 & Setembro - Dezembro 2021 & p. 177 - 196 \\
\hline
\end{tabular}


educacional, quer dizer, duas partes correspondentes e complementares de um mesmo problema, o complexo sistema de reprodução e produção das estruturas de valores, no qual os indivíduos assentam suas escolhas de vida e, às vezes, até a dor (ALTHUSSER, 2000).

\section{A teoria do discurso: o laço social}

Do encontro entre política e psicanálise, o médico e psicanalista francês Jacques Lacan (1901-1981) introduziu uma virada na tradição freudiana, dando destaque à leitura do marxismo sobre a consciência do ser social, algo que talvez tenha diferenciado o campo lacaniano pela mudança de perspectiva com a presença da linguagem e da teoria social. Tal posição se encontra em diversas obras do autor francês, particularmente em $O$ avesso da psicanálise (1969/70); Discurso de Roma (1953); De um discurso que não fosse semblante (1971), entre outras. De fato, uma das intenções de Lacan com a psicanálise era construir uma clínica com interlocuções no espaço social, histórico e estético que possibilitasse também outra hermenêutica do sujeito, na tentativa de explicar a existência de uma estrutura objetiva e intersubjetiva na aparente realidade massificada. Logo, a análise do discurso surge como representante dessa totalidade.

Lacan apoiou-se na metapsicologia freudiana para operar uma leitura de fatos e fenômenos sociais na intenção de problematizar e desvendar os jogos de poder por trás do campo social (ZIZEK, 2010). Entretanto, essa realidade por onde a ciência social apreende seu campo de observação não busca elucidar uma instância inconsciente no interior do sujeito, um aparelho psíquico que é estruturado como uma linguagem, no qual se supõe a possibilidade de revelar o dual embate entre mundo e pensamento. Em Lacan, percebe-se o intuito de aplicar a psicanálise no terreno social, considerando que o conhecimento psicanalítico abre condições de levantar hipóteses antropológicas, políticas e, talvez, orientar algumas questões fundamentais no espaço educativo, como a disposição de interrogar o papel tradicional do professor na figura do mestre.

No primeiro momento de reflexão, em seu Seminário XVII, intitulado $O$ avesso da psicanálise (1969-1970), Lacan apresenta a teoria dos discursos a partir de quatro estruturas básicas, denominadas por ele de neologismo quadrípodes: o discurso do mestre, o discurso da histérica, o discurso do universitário e o discurso do analista. Dois anos após a publicação da obra $O$ avesso da psicanálise, em 1972, Lacan acrescenta um quinto discurso, designado o discurso capitalista, visto como um instrumento de linguagem que instaura as relações de poder e permanência do status quo, pensado

\begin{tabular}{|c|c|c|c|c|}
\hline Qevista Dialectus & Ano 10 & n. 24 & Setembro - Dezembro 2021 & p. $177-196$ \\
\hline
\end{tabular}


também como uma cadeia de significados/significantes que estrutura operações de dominação, principalmente por intervenções políticas e econômicas. Não obstante, o discurso capitalista extrai, da linguagem, meios e dispositivos de controle, vigilância e alienação que, na trilha da modernidade e das ciências, reforçam o quadro socioeconômico, estimulando o fetichismo das coisas, colonizando as mentes e isolando os sujeitos, na tentativa de explorar os desejos e capturar nossas pulsões (LACAN, 1954/1992). Comumente, a cultura econômica impõe um deslocamento contínuo via fetichismo de mercadoria e por outras formas de prazer. Fica claro que o capitalismo pretende ocupar o espaço do gozo ${ }^{5}$ nos sujeitos, em uma lógica de produção inspirada nos sujeitos insaciáveis. Como já afirmou certa vez Fredric Jameson, na obra Pósmodernismo, ou, a lógica cultural do capitalismo tardio: "O capitalismo dominou o inconsciente humano" (2018). Lacan afirma, inclusive, as possíveis conexões do discurso capitalista com a dinâmica da estrutura social, por exemplo, na questionável ideia sobre meritocracia, na ilusão do empreendedorismo, no dízimo ou na naturalização do caos.

Lacan aponta o conceito de discurso através do laço social. Esse é entendido como os mecanismos que sustentam as relações do discurso, identificado em tipos de enunciados ou expressões, todavia não se limita à utilização de palavras e vocábulos, dado que pode dispor de coisas, pessoas, territórios, tradições, dentre outros, pois o discurso excede as palavras, é carregado de sentido, materializando espaços para subsistirem determinadas relações e seus elementos (LACAN, 1969/70). Dessa maneira, os laços sociais são a própria forma de criar vínculos e conexões dentro da cultura. Não obstante, o laço social não deve ser confundido por um determinismo social, condicionado às condições pré-existentes, mas articulado à singularidade do sujeito e de suas escolhas individuais.

Dada essa prévia noção, a teoria dos discursos é elencada por fórmulas que representam as estruturas como laços sociais, elas, por sua vez, estabelecem os lugares onde os discursos são fabricados no campo social (QUINET, 2012, p.74). Dito isso, a constituição dos modos de cultura, as características das civilizações, a difusão de normas, modelos de educação ou orientações sexuais, são, por exemplo, formas de fazer laços sociais. Ademais, elas vão encaminhando a transmissão e produzindo a dinâmica dos discursos, que expressam uma das ordens de realidade incorporada pelo sujeito. A

5 Lacan introduz o conceito de gozo a partir da dialética do amo e do escravo, quando argumenta que o sujeito encontra seu gozo no outro, ou mesmo no seu algoz. O gozo é a busca pela satisfação imaginária.

\begin{tabular}{|l|l|l|l|l|}
\hline Qovista Dialectus & Ano 10 & n. 24 & Setembro - Dezembro 2021 & p. 177 - 196 \\
\hline
\end{tabular}


realidade também é dada pelas estruturas da linguagem, as quais, nesse aspecto, também possuem uma dimensão intrapsíquica que organiza os diferentes modos objetivos e subjetivos dos sujeitos (LACAN, 1954/1992, p. 221).

Lacan elucida a configuração dos discursos dominantes nas estruturas e em suas representações pelos giros discursivos ${ }^{6}$, de maneira que, ao destacar a utilização social da linguagem nas relações de troca, Lacan observa que o discurso envolve as formas de reproduções no status quo, os agendamentos do sujeito e tantas outras ferramentas alienantes para a sociedade. Do ponto de vista macro, o discurso dominante está inserido na lei, do governo, do conhecimento, na religião, cujo lugar lhe investe de verdade e autoridade sobre os outros, impondo a ordem dominante, a qual vigia e esvazia qualquer possibilidade de subjetividade. A forma plástica e fluida penetra nas conversas cotidianas, na comunicação audiovisual e no mundo virtual dos algoritmos que multiplicam cada vez mais seu alcance (LACAN, 1966, p. 65).

No que diz respeito à teoria do discurso, Lacan enfatiza que o próprio sujeito está estruturado em seus significantes, ou seja, nas suas representações subjetivas e objetivas a nível consciente e inconsciente pela forma com a qual se corresponde com o seu corpo, com o outro e com o grande Outro (A) (ZIZEK, 2010, p.17). A fala sustenta determinados códigos linguísticos que se transformam em instrumentos sobre pequenos outros, como uma etiqueta quase invisível que é transmitida na malha social. Freud já evidenciava os efeitos dos discursos a nível individual e social, na trama da civilização que luta pela sobrevivência. A respeito da linguagem, Lacan afirma:

Tal posição implica os efeitos de linguagem na determinação do ser: Porque somos (...) resultado do emprego da linguagem. Quando digo o emprego da linguagem, não quero dizer que a empreguemos. Nós é que somos seus empregados. A linguagem nos emprega, e, é por aí, que aquilo goza (LACAN, 1969/70, 2016, p. 62).

Uma das grandes descobertas da Psicanálise encontra-se em notar que a linguagem tem efeito sobre o sujeito, de estabelecer agendamentos, produzindo processos, silêncios, ações e até ócio, determinando a vivência de quem fala, inclusive na sua relação com o outro. Não obstante, a linguagem nos moldes da lógica neoliberal tornou-se mais um nó para os laços sociais através das condições de experiência e de existência. $\mathrm{O}$ estruturalismo imprimiu uma ideia de sociedade permeada pela linguagem,

${ }^{6}$ Nota: Giros discursivos são as trocas de posição entre os matemas, gerando assim os tipos de discursos.

\begin{tabular}{|l|l|l|l|l|}
\hline Revista Dialectus & Ano 10 & n. 24 & Setembro - Dezembro 2021 & p. 177 - 196 \\
\hline
\end{tabular}


convergindo-a em fator social, em um tratamento que começa pela fórmula entre sentido e unidade (DUCROT, O. \& TODOROV, T. 1973). Nesse ínterim, faz-se necessário saber os pressupostos da entrada da linguagem na psicanálise, pois antes de qualquer análise do discurso, primeiro se estuda a linguagem.

Tecendo algumas considerações sobre a relação que a psicanálise lacaniana mantém com a linguagem, no sentido de entender em que momento para a teoria dos discursos passou o lugar da linguagem para o discurso, quando uma sobrepõe a outra, haja vista que a noção própria do termo em Lacan denunciou a importância do contexto histórico na possibilidade de saber e ter acesso aos "jogos de linguagem" dos discursos. Em linhas gerais, o campo da linguagem é um balizador das relações entre o sujeito e o outro, entre o homem e o mundo, e manifesta as representações mediadas e formadas pelos indivíduos (LACAN, 1969/70), ao passo que a compreensão ampliada das formas de comunicação trouxe uma correspondência maior entre a análise dos discursos contida nos estudos da linguagem pelo estruturalismo Saussuriano com a nova base lacaniana.

Com isso, precisamos destacar que o termo linguagem, muitas vezes, tem uma noção polissêmica, apresentando significados variados e transitórios de acordo com o uso semântico ou histórico-cultural empregado (DUCROT, O. \& TODOROV, T. 1973). O termo também pode designar realidades sociais diferentes pelo movimento combinatório dessas referências. Pela ampla flexibilidade, a linguagem vai ganhando complexidade podendo ser entendida em função dos sistemas simbólicos e socioculturais presentes.

Nos primeiros anos de seus ensinos, Lacan se preocupou em elaborar grafos $(S 1, S 2, \$, a)$ para melhor ilustrar a teoria dos discursos, um tipo de ordenação para representar e expressar as maneiras de fazer uma leitura sobre o real, através da fala de quem transmite, da escuta do interlocutor e da transmissão do escrito. É da hipótese de observá-las que Lacan desenvolve uma álgebra própria. Longe de ser um conhecimento, como proposições de Verdade, a teoria do discurso pode ser definida a partir da sua correspondência com o papel da fantasia na estrutura psíquica, ou seja, na interface entre simbólico e real, boa parte das relações do sujeito com o mundo se inscrevem no inconsciente, categorizadas em forma de letra para a psicanálise, e examinadas através da representação em cadeia de significantes, em que diante da vulnerabilidade, do assombro e do traumático, faz sintoma e deixa traços (LACAN, 1971/2008).

Com efeito, ressaltamos o contexto histórico e cultural em que Lacan desenvolveu a teoria do discurso, para elucidar seu objetivo em traçar um comparativo 
que explicaria a captura do sujeito pelo capitalismo através do campo dos discursos. Esse panorama sinaliza as ideias revolucionárias e o cenário geopolítico tenso da época que repercutiram na tradição acadêmica, que abrangem o movimento estudantil francês, as greves operárias, a guerra do Vietnã, o assassinato de Martin Luther king e os avanços tecnológicos dos anos 60. O embate lançou críticas sobre o desenrolar assumido pela ciência nos centros universitários de pesquisa, em razão da crescente desigualdade social com o avanço do capitalismo. Havia um desengano em relação à razão iluminista e um alerta ao sistema corrosivo do capital, que necessitava de mais engajamento estudantil e quebras de paradigmas. O movimento de Maio de 68 em Paris, com o lema "é proibido proibir", questionava justamente as estruturas institucionalizadas que incorporavam o poder e seus modos de constituição e transmissão. Inclusive Lacan não passou despercebido às críticas, acusado de manter uma posição política conservadora e de exercer uma prática psicanalítica burguesa, foi alvo de grande rejeição. Em resposta, Lacan propôs o Seminário XVI, intitulado De um Outro ao outro (1968/69), em que aproximava a Teoria Marxista do mundo psíquico da Psicanálise, cuja entrada em jogo permitia falar da Mais-Valia enquanto possibilidade do Mais-Gozar, muito utilizada no consumo. Nesse mote, introduziu o lugar essencial do objeto a (nossos desejos e impulsões) ao situá-lo também na passagem da função simbólica da Lei (a função paterna de vigilância ou controle), onde evidenciou a atenção preocupada de Lacan com fatos nada triviais do seu tempo.

Contemporaneamente, no plano do Mal-estar, as patologias sociais representam o nível mais alarmante do processo de coisificação e instrumentalização do saber e da vida, geralmente lado a lado com a sensação de insegurança e pânico naturalizada. Os jovens parecem mais sensíveis a esse fenômeno moderno, pela necessidade de reconhecimento, de identificação e de liberdade inevitáveis, que são muitas vezes vivenciadas e descobertas no âmbito escolar, onde professores e professoras ficam impotentes perante tal complexidade psicossocial, uma busca angustiante que pode terminar de maneira trágica, se mal compreendida (FREUD, 1997).

Como podemos ver, certas condições culturais e políticas agravam a sensação de Mal-estar, oriunda das tensões que a cultura civilizacional produz nos corpos, o vazio chega com a ausência da experiência vital da dimensão subjetiva, da instância do "eu". Talvez na escola, esse Mal-estar incompreendido seja proveniente de uma cultura já adoecida e, por isso, as soluções devem ser pensadas por outra ordem, seja pela percepção 
em relação às mudanças de comportamento de crianças e jovens, pela falta de interesse sem explicação, pelas práticas violentas, pela postura excessivamente narcisista, bem como na origem de transtornos, na evasão, dentre outros. São alguns sintomas agudos que devem ser avaliados a partir da implicação do discurso capitalista no campo educacional, não apenas em sua complexidade geral, mas naquilo em que constituem e alimentam o quadro desse fenômeno prematuro, principalmente em um ambiente que propõe um ideal de partilhas para um bom desenvolvimento, mas que torna-se fictício e impotente.

No tocante às novas formas de tratamento dos sintomas, às transformações na configuração familiar, às novas relações estabelecidas no mundo do trabalho, como também ao novo perfil de produção e circulação das mercadorias no capitalismo global, podem representar uma ruptura, refletir as forças sociais e militantes que pulsam por voz no tempo presente, impondo-se tanto no eixo da cultura como nos espaços urbanos. Essas são pensadas em termos de dissolução da modernidade, por oposição à aceleração do tempo que sustenta a alienação e na domesticação da natureza. O freio nasce geralmente no Mal-estar, como nunca antes, e acompanha o sujeito deprimido, o ansioso, o estressado no caos das metrópoles, tenciona conflitos de guerra e paz até confeccionar novas doenças e emergências clínicas. A teoria dos discursos é, nesse sentido, um caminho para refletir e inspirar novas respostas a essa totalidade de fenômeno que está relacionada ao processo de reconfiguração do vínculo social, posto que a psicanálise poderia fornecer uma mudança de perspectiva (LACAN, 1968/2008).

As possibilidades e os limites sobre a relação entre psicanálise e educação contemporânea podem ser pensadas na relação entre quem ensina e quem deseja aprender, entre o espaço de aprendizagem e as dimensões preestabelecidas, em que o agente é o professor e o aluno é o outro. Porém não somente uma sala de aula é necessária para estabelecer vínculos ou criar relações, mas o ato de ensinar e transmitir liga aquilo que possibilita essa interação entre pares (LACAN, 1969/70). O ato que funda o laço social é sempre do agente do discurso (professor), pois segundo Lacan o fato de dizer gera acontecimento, funda a própria experiência discursiva. E, quando o ato se dirige ao outro nascem conexões, a práxis do laço social torna-se concreta junto aos elos formados ali. Nesse aspecto, indicaria a possibilidade ou impossibilidade de certos encontros sociais, do agente com o outro, da produção com a verdade (VOLTOLINI, 2011).

\section{O discurso capitalista: o triunfo do discurso do mestre}


Com o reconhecimento do discurso capitalista presente nas dimensões da vida, visto nos efeitos dos laços sociais e na educação, modificando profundamente as relações e a formação do sujeito, pode-se dizer que esse discurso adquiriu as seguintes abrangências: nas políticas educacionais, na ciência, na criação do capital humano e no próprio capital financeiro. Dentre essas, as políticas educacionais são talvez aquelas que melhor representam o impacto social da onda neoliberal, frente à responsabilidade de atuação do Estado em planejar e executar as metas e prioridades. Assim, notar quais são os pilares que gestam as medidas governamentais é saber o grau de comprometimento na redução das desigualdades e a plena garantia de direitos, em que a ausência de políticas públicas voltadas para a educação comprova uma estagnação e desmonte na modernização da escola, como resultado, o Mal-estar penetra em outros poros e semblantes, em um sentimento difícil de disfarçar.

A partir da hegemonia econômica do capital financeiro na educação, o próprio capital torna-se um significante mestre (S1). O mestre, nesse cenário, não fica reduzido a símbolos ou a figuras tradicionais, mas ao imaginário, ao peso cultural que imprime formação de condutas. Segundo Lacan (1969/70), nas estruturas determinantes da linguagem, o capital passa a atribuir o lugar daquele que desempenha as formas de fazer subordinados, definindo a legibilidade de qualquer tipo de discurso. Nele coabita a relação entre produção e verdade, posto que faz o jogo com os valores da verdade e sua circulação tem um alcance de gerenciar o conhecimento científico. E logo, de saída, partese de uma "razão" preformada, que resulta a posteriori na direção de um saber que produz dominados (LACAN, 1969/70). Nesse sentido, do ponto de vista pedagógico, o capital assume a posição de poder do mestre, e, concomitantemente, fiel às velhas tradições do condicionamento de um ensino programado, associacionista e mecanicamente ordenado.

Em seu aspecto mais amplo, a inscrição do discurso capitalista na educação surge com a adoção de determinadas agendas internacionais (OCDE, Banco Mundial, FMI e Comissão Europeia) para as políticas educacionais, que também se utilizam das políticas públicas para intervir no processo de legislação, informação e cidadania (LAVAL, 2004). Na verdade, essas políticas educacionais seguem o imperativo de uma cultura científica restrita, que ampara e reforça a verdade sobre o poder do capital. De fato, o sujeito tem o seu papel delimitado pelas políticas educacionais, exigindo-lhe mão de obra qualificada para competir no mercado com outros sujeitos, na ilusão de que assim 
possuam meios e poder de barganha para uma boa posição na escala de divisão de trabalho, e no fim serão encaminhados para produzir mais, consumir mais e gozar mais. As possibilidades de futuro e novas oportunidades são geradoras de grandes angústias e síndromes na atualidade, os indicadores da OMS já enquadram a depressão como uma das maiores patologias incapacitantes pelo alto índice de afastamento no trabalho (DALGALARRONDO, 2018). Dessa forma, o Estado neoliberal banaliza a internacionalização do direito à educação de qualidade e de Bem-estar social, radicalizando e acelerando os processos de exclusão social e adoecimento.

Em termos de capital humano, a educação no mote do discurso capitalista passa a aplicar na escola os valores do mercado, os conteúdos curriculares necessários e o incentivo a determinadas carreiras, assim como sustenta nos bastidores a correspondência conveniente entre o crescimento econômico da elite e o nível educacional, de modo que o Estado neoliberal será o grande favorecido com a produtividade. Mostra-se mais uma vez que o ensino público dificilmente mantém soluções e recursos para uma formação ampla e emancipada, mas sim, permanece preso à aceleração de novas massas de trabalhadores, norteado pela empregabilidade e pelo empreendedorismo. Não obstante, a face da democracia dificilmente se revela exclusivamente com o direito ao acesso à educação, pois o desemprego evidencia a fragilidade do vínculo entre diploma e emprego, criando uma bolha de profissionais que ao longo da vida exercem várias atividades para sobreviver (CÁSSIO\&HADDAD, 2019).

Podemos observar nos últimos anos que houve um aumento no interesse sobre as metodologias de gestão nas políticas educacionais, algo que sinaliza como a educação se transformou em um serviço prestado ao mundo econômico. Dada a crescente incorporação desses valores às categorias econômicas, o ideal igualitário e humanista foi invertido, admitindo-se pensar o sujeito como um recurso humano, e não mais como pessoa humana (LAVAL, 2004). Assim, sem dúvidas, muitos professores e professoras acabam participando menos das decisões nas escolas e conhecendo pouco a realidade da comunidade, pois são barrados por atividades burocráticas e exaustivas, ou por cobrança nos índices de aprendizagem e avaliação. O próprio modo sutil de cerceamento do seu trabalho afasta o engajamento.

Diante disso, o questionamento passa para outro ângulo de interesse, sobre a real abertura das escolas às questões igualitárias, na ruptura dos modos disciplinares e conteudistas de ensino, como também em mais abertura para espaços de convivência e 
maior tempo para as práticas extracurriculares. Sendo assim, percebemos o adoecimento precoce de crianças e jovens dentro das escolas, pois, independente da razão ou da natureza do sofrimento, ainda assim é notória uma parcela desse discurso capitalista no cerne do Mal-estar vivido por esses indivíduos (SAFATLE, 2021). A pressão pelo sucesso escolar, a angústia sobre a escolha profissional, as dificuldades de aprendizagem, a tensão de uma rotina acelerada de estudos, o medo do fracasso e a decepção familiar são alguns sentimentos que acompanham os jovens. Enquanto na outra ponta das classes sociais, o estudante de escola pública vive a dupla jornada de trabalho e estudo sem ter garantias reais de oportunidades, sofrendo o preconceito excludente de classe e cor, e perdendo a confiança em si mesmo. Situações de sofrimento psíquico que são ampliadas pela lógica neoliberal que influenciam muitas escolas com seu discurso capitalista, na atitude sorrateira de esconder o interesse de padronizar massivamente os sujeitos (CÁSSIO\&HADDAD, 2019).

Os efeitos do Mal-estar são muitos, em um plano individual e coletivo amplo o estado de ansiedade e agonia retrata o sintoma da vida nua da sociedade, a transformação da vida humana em objeto e intolerância, regulada por dispositivos de poder. O sofrimento biopsicossocial na contemporaneidade ocorre através da própria dinâmica civilizacional que acentua e radicaliza a dominação dos corpos (FREUD, 1997). Por conseguinte, a relação de confiança e segurança nas instituições centrais da sociedade sofrem graves abalos, rompimento com o velho modelo deixando o sujeito à deriva, sem uma alternativa aparente. Na escola, talvez, isso seja mais percebido, dada a necessidade de autoridade (figuras paternas), na adoção de uma psicologia moral para adaptar os desajustados, na medicalização precoce, nos bullyings, no disciplinamento e na ausência de atitudes reflexivas. Por isso, o mestre capital funciona como um regulador das dinâmicas nas instituições e um reprodutor das estruturas ideológicas (ALTHUSSER, 2000).

Por conseguinte, após os avanços da neurociência, buscou-se por muito, entender os fenômenos mente-cérebro pautando-nos na bioquímica e em dados estatísticos, com objetivo para traduzi-los em um formato operacional para as massas e para o mercado farmacêutico (DALGALARRANDO, 2019). Essa instrumentalização mostra uma preocupação exagerada com o empírico e com o processamento estatístico de informação, com pretensões de construir leis e teorias específicas para associar a prognóstico de condutas sociais e decifrar comportamentos, puxando a reboque o 
problema da medicalização. Neste caso, a produção de conhecimento no âmbito das ciências humanas fica limitada de dados coletados, dependendo de explicações casuísticas. Disto resulta uma gama de conceitos voltados à análise de dados fixos e estáveis, o que contribui para lentamente estabelecer modelos comportamentais e excluir a singularidade do sujeito, onde ao menor desvio padrão é solucionado com psicotrópicos (DALGALARRANDO, 2019).

Voltando aos pressupostos teóricos, Lacan afirma que o discurso capitalista foi determinado por razões históricas, anunciou-se com articulações na estrutura do discurso do mestre, emergiu como um novo tipo, que há pelo menos três séculos vem paulatinamente ecoando em nossas práticas. Essa nova modalidade, proclamada por Lacan como discurso capitalista, apresenta uma fórmula distinta dos demais por se integrar aos quatro matemas e assim dá conta do universo discursivo (LACAN, 1969/70). Em uma viagem à Itália, em 1972, Lacan expôs em termos históricos um conjunto de sequências daquilo que formaria esse quinto discurso capitalista, sinalizando os laços habilidosos da linguagem protestante e do protagonismo liberal do capitalismo nas práticas culturais e histórico-sociais e, segundo o autor e psicanalista Antônio Quinet (2012), Lacan se inspirou nas teses clássicas de Marx Weber, porém, sem explicar explicitamente sua particular aproximação. Vamos às palavras de Lacan:

\begin{abstract}
A história mostra que o discurso do mestre viveu durante séculos de modo proveitoso para todo mundo, até chegar a certo desvio que o transformou, por um ínfimo deslizamento que passou despercebido até para os próprios interessados, em algo que o especifica desde então como o discurso do capitalista... O discurso do capitalista se distingue pela Verwerfung, pela recusa, pela expulsão ao exterior de todo o campo do simbólico... recusa de quê? Da castração. Toda ordem e todo discurso que se aparenta com o capitalismo deixa de lado isso que de maneira simples chamaremos as coisas do amor. E isso, meus bons amigos, não é pouca coisa! E é por isso que, dois séculos depois desse deslizamento - chamemo-lo, por que não, calvinista -, a castração fez finalmente sua entrada sob a forma do discurso analítico. (LACAN, 1969-1970/199, p. 31).
\end{abstract}

Ao mesmo tempo, o discurso capitalista também emergiu em consequência do encontro do saber científico e técnico da primeira metade do século XVIII, como se fosse uma transformação do discurso do mestre. Precisamente, surge com as revoluções burguesas e com a revolução industrial, invadindo determinadas classes, criando vínculos de experiências e novas ordens de conduta política e econômica, na função de agente que atualiza o milenar discurso do mestre em crise, pois realizou interferências no desejo e no

\begin{tabular}{|l|l|l|l|l|}
\hline Q Ponista Dialectus & Ano 10 & n. 24 & Setembro - Dezembro 2021 & p. 177 - 196 \\
\hline
\end{tabular}


sintoma social. Nessa circunstância, os laços sociais se estabelecem em lugares já predeterminados em nossa sociedade, ocupando sempre duas posições, o agente (dominante) e o outro (dominado). No laço social, um não existe sem o outro, a exemplo do vínculo entre patrão e empregado e na relação entre professor e aluno. A realidade social é composta por laços sociais que Lacan também chama de aparelhos de gozo, na medida em que essas relações promovem a satisfação na convivência ou coabitação com o outro. Com efeito, está delimitado pela cultura, e, portanto, traz assim suas referências simbólicas para saciar suas pulsões de vida e morte (LACAN, 1969/70).

$\mathrm{Na}$ atual modernidade científica e capitalista, foi inaugurado um novo tipo de economia política, que não somente determina as regras do mercado, mas também é uma economia libidinal, no sentido de capturar a satisfação pelo saber técnico, com o fim último de manter o status quo. Nas leituras de Marx, Lacan percebe que sua denúncia sobre o processo de espoliação merecia observações, pois este "a faz sem se dar conta de que é no próprio saber que está o seu segredo - como o da redução do próprio trabalhador a ser apenas valor" (LACAN, 1969/70, 2016, p. 21). Mas considerando a Mais-Valia na “topografia" libidinal, Lacan acreditava que o processo de espoliação tange ao gozo, na articulação com o lugar de saber, assim, quando fundamentalmente, na modernidade vem a ser marcada pela união da ciência universitária com o capital.

Lacan chega a falar de artefatos que a ciência permite fabricar e enviar ao mercado para o consumo massivo e que estão destinados à única e rápida necessidade, sendo tão logo substituídos por outra fonte de desejo, funcionando como elemento catalizador, de transferência, de desejo, de mais-gozar. Entretanto, rapidamente caem na obsolescência, uma após a outra, em uma dinâmica voraz de busca por satisfação (1969/70, 2016, p. 188). Considerando dessa forma, o sujeito se torna um desconhecedor da sua servidão, na predominância daquilo que a psicanálise chama também de "narcisismo" e por onde o discurso capitalista procura alimentar.
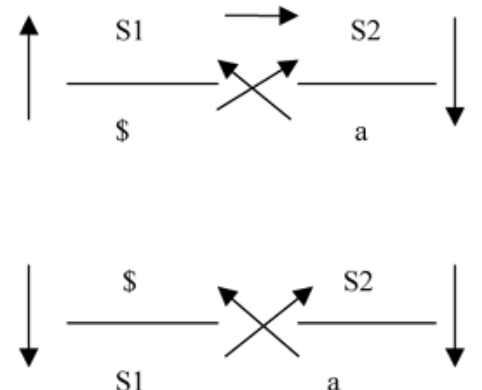

Discurso do Mestre

Discurso do Capitalista 
É fato, que o capitalismo pode ser titulado de discurso do mestre, pois cria as estruturas, explora as condições e se apropria dos espaços onde se instala o saber, por exemplo, nas universidades ou em programas científicos, vigorando assim na modernidade o discurso do capitalista (mestre capital), como um tipo de significantemestre, pois ali ele ocupa as posições de ordenar e gerar sentido às significações, fazendo uma tirania com o saber (LACAN, 1969/70, p.138).

Dessa maneira, Lacan propõe o discurso capitalista como uma conversão ou mutação do discurso do mestre. As revoluções econômicas e sociais constituíram um novo sistema. O autor afirma que o capital é o mestre contemporâneo, e que o Mal-estar atual é justamente proveniente desse mestre capitalista. A ascensão do capitalismo, associada à ciência, ocasionou grandes transformações culturais e históricas a ponto de alterar negativamente as formas de vínculo social, sobretudo no espaço escolar.

\section{CONCLUSÃO}

Dado o exposto, analisar a educação escolar a partir do cenário atual não é uma tarefa fácil, sobretudo no momento em que se observam as ideologias capitalistas que mantêm as estruturas sociais e suas instituições. Por isso, pensar em uma escola aberta, que incentive a atividade crítica e reflexiva, assim como que tenha um olhar sensível para o aluno, sua história e escolhas, torna-se de fato um desafio pungente. Contudo, muitos professores e outros profissionais da educação buscam de certa forma resistir e não aceitar de pronto a lógica capital que ordena o campo educacional.

Percebemos que a padronização do ensino é um imperativo do mercado, uma vez que o próprio ensino já se transformou em produto de consumo. Em vista do avanço e das mudanças econômicas das sociedades de capitalismo, os discursos sobre as políticas educacionais vão se tornando a linha de frente para a consolidação da predominância do Estado neoliberal, ou seja, o laço social que estabelece os vínculos e as experiências do sujeito já está capturado pelo mestre do nosso tempo, o capital. A escola pode ser considerada um microcosmo quando retrata a existência desses conflitos e das tensões humanas originárias do nosso tempo, às vezes identificada na perda de sentido ou na ansiedade entre os estudantes, um Mal-estar não limitado a estruturas sociais específicas, mas que até abrange as relações entre professor-aluno ou professor-instituição de ensino.

Tendo em vista tal problemática, a resposta imediata para a pergunta "Para onde vai a educação" presume-se que ainda será sustentada em nosso tempo, o triunfo do 
discurso do mestre, pelas vias normalizadoras, pela lógica gerencial e acumuladora, em uma "pedagogia comportamental" apenas, principalmente das despesas educativas tendo que ser rentáveis. E, assim, a nossa dinâmica interior vai reelaborando vínculos, sublimando o vazio ou transbordando mais sintomas, no ímpeto de encontrar uma rota de fuga.

Os desdobramentos dizem respeito aos efeitos do discurso capitalista e à ordem dos mercados comuns na educação, retornando e trazendo à tona as formas de sofrimento dos sujeitos, advindas também da perda de liberdade por ele próprio compor essa engrenagem.

\section{REFERÊNCIA}

ALTHUSSER, Louis. Freud e Lacan, Marx e Freud. $4^{\circ}$ edição, Rio de JANEIRO: Edições Graal, 2000.

CÁSSIO, Fernando \& HADDAD, Sérgio. Educação contra a barbárie: por escolas democráticas e pela liberdade de ensinar. $1^{\circ}$ edição - São Paulo: Boitempo, 2019.

DALGALARRONDO, Paulo. Psicopatologia e Semiologia dos Transtornos Mentais. 3 edição, Editora ArtMed, Porto Alegre, 2019.

DUCROT, O. \& TODOROV, T. Diccinonario enciclopédico de las ciencias del lenguaje. Buenos Aires: Siglo Veintiuno, 1973.

FREUD, Sigmund. O mal-estar na civilização (1930): Trad. de José Octávio de Aguiar Abreu. Rio de Janeiro: Imago, Ed. 1997.

LACAN, Jacques. O avesso da psicanálise (1969-1970). O seminário, 17. Rio de Janeiro: J. Zahar, 2016

p. $869-892$.

A Ciência e a verdade (1966). Escritos. Rio de Janeiro: Jorge Zahar, 1998.

Para além do imaginário, o simbólico ou do pequeno ao grande outro. (1954/55). O Seminário livro 2: O EU na teoria de Freud e a Técnica da psicanálise. 3 ed. Rio de Janeiro: Jorge Zahar, 1992. p. 221-344

De um Outro ao outro (1968-1969). Rio de Janeiro: J. Zahar, 2008.

JAMESON, Fredric. Pós-humanismo, ou, a lógica cultural do neocapitalismo global. Tradução André Magnelli. Editora Anna Blumme, São Paulo, 2018.

LAVAL, Christian: A Escola não é uma empresa: O neoliberalismo em ataque ao ensino público. Tradução Mana Luiza M. de Carvalho e Silva, Londrina-PR, Editora Planta, 2004.

MÉSZÁROS, István. Marx: A teoria da Alienação. Tradução Waltensir Dutra. Rio de Janeiro, Zahar Editores, 1981

MOSCOVICI, S. A representação social da psicanálise. Rio de Janeiro, Zahar. 1978

\begin{tabular}{|l|l|l|l|l|}
\hline Revista Dialectus & Ano 10 & n. 24 & Setembro - Dezembro 2021 & p. 177 - 196 \\
\hline
\end{tabular}


J.-D. Nasio. Cinco lições sobre a teoria de Jacques Lacan. Rio de Janeiro: Jorge Zahar, 1995

SAFATLE, Vladimir. Neoliberalismo como gestão do sofrimento psíquico. Belo Horizonte, $1^{\circ}$ edição, Editora Autêntica, 2021, p. 17-46

SAUSSURE, F. Cours de linguistique générale. Paris: Payot, 2005

QUINET, Antonio. As quatro mais um: condições da análise. $12^{\circ}$ edição, Rio de Janeiro: Jorge Zahar Editor, 2012.

VOLTOLINI, Rinaldo. Educação e Psicanálise. Rio de Janeiro: Zahar, 2011.p.65

ZIZEK, Slavoj. Como ler Lacan. Tradução Maria Luiza X. Rio de Janeiro: Zahar, 2010. 